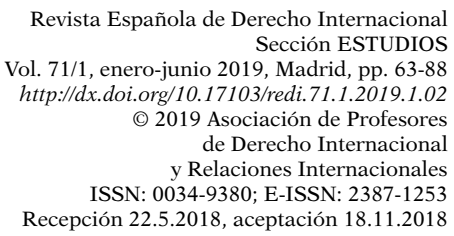

\title{
LA CUMBRE DE LAS AMÉRICAS: UN ESPACIO PARA LA COOPERACIÓN SIN APENAS PROYECCIÓN NORMATIVA
}

\author{
Cástor Miguel DíAz BARRADO*
}

SUMARIO: 1. INTRODUCCIÓN.-2. CONFIGURACIÓN DE LA CUMBRE DE LAS AMÉRICAS: FACTORES POLÍTICO-JURÍDICOS DETERMINANTES.-2.1. La Cumbre de las Américas como expresión del panamericanismo: la escasa incidencia en la dimensión jurídica.-2.2. La cambiante situación política en la Cumbre: la inevitable falta de acuerdos.-3. CONTRIBUCIÓN DE LA CUMBRE EN LA FORMACIÓN DE PRINCIPIOS DEL ORDEN INTERNACIONAL.-3.1. El "principio democrático»: aportaciones específicas en el ámbito jurídico.-3.2. El Libre Comercio como principio en las relaciones entre los Estados americanos: incertidumbres sobre su naturaleza y grado de aceptación.-4. CONCLUSIONES.

\section{INTRODUCCIÓN}

La práctica en la celebración de las distintas Cumbres de las Américas revela, en esencia, un foro de debate y discusión destinado a cumplir algunas funciones en los ámbitos de la concertación política y la cooperación internacional pero que apenas ha logrado resultados efectivos, incluso en estos campos $^{1}$. En perspectiva de concertación política se avanza poco puesto que,

* El presente trabajo se realiza en el marco del proyecto I+D titulado «Actores económicos internacionales y derechos humanos. Especial relevancia para España», DER2014-55484-P. También se realiza como actividad del «Laboratorio iberoamericano para el análisis de la cultura, el comercio y el desarrollo como elementos de la cohesión social en Iberoamérica», proyecto concedido por la AECID, en 2008, siendo el investigador principal. Cástor Miguel Díaz Barrado es catedrático de Derecho internacional público en la Universidad Rey Juan Carlos de Madrid (castordiaz1@gmail.com). Todas las páginas web de referencia han sido consultadas por última vez el 28 de noviembre de 2018.

${ }^{1}$ La bibliografía sobre estas Cumbres es escasa y sobre los aspectos jurídicos prácticamente inexistente. Algunos títulos: FeInberg, R. E. y Rosenberg, R., «Conociendo a fondo las cumbres: evaluación de la cumbre de las Américas de Santiago y sus consecuencias», Síntesis, Revista Documental en Ciencias Sociales Iberoamericanas, 1999, núms. 31-32, pp. 75-91; Álvarez Romero, J. M., «La cumbre de las Américas», Veintiuno: Revista de Pensamiento y Cultura, vol. 24, 1994, pp. 129-132; MIGNEAUlT, D., «En route vers le V Sommet des Amériques», Centre d'études interaméricaines, diciembre de 2008, pp. 1-15; y PAZ BARNICA, E., "La cumbre de las Américas y la cooperación hemisférica», Cursos 
en la mayoría de los casos, se dejan entrever los profundos enfrentamientos y discrepancias que habitan en la región. Sin embargo, de forma puntual, se han alcanzado grados aceptables de concertación política como sucedió con ocasión de la VI Cumbre, celebrada en Panamá, en 2015, que plasmó el acuerdo entre los Estados Unidos y Cuba para que se produjera el «deshielo» entre los dos países ${ }^{2}$. En la óptica de la cooperación no se han alcanzado tampoco resultados espectaculares ni tan siquiera la Cumbre tiene capacidad para sentar las bases de una cooperación eficaz entre todos los Estados. El fracaso de la iniciativa tendiente al establecimiento de un Área de Libre Comercio de las Américas (ALCA), que se explicitó en la Cumbre que tuvo lugar en Mar de Plata, en 2005, así lo atestigua ${ }^{3}$.

No es fácil encontrar trabajos doctrinales que aborden esta Cumbre desde una perspectiva jurídica, lo que permitiría conocer los avances normativos que ha propiciado o que han tenido lugar al hilo de estas reuniones al más alto nivel. La visión de la Cumbre es eminentemente política y se concibe como un espacio que no está destinado a consagrar principios de naturaleza jurídica y, mucho menos, la adopción de acuerdos internacionales que tengan carácter obligatorio. La celebración de la Cumbre no ha auspiciado la celebración de un solo tratado internacional (exceptuando como veremos el Acuerdo ALCA) ni tampoco instrumentos que tengan un cierto valor normativo. Puede pensarse que esto es habitual en Cumbres de este tipo y que, además, responde a lo que se ha venido a denominar la «diplomacia de las Cumbres» ${ }^{4}$. En consecuencia, no entraría dentro de sus objetivos plasmar acuerdos internacionales ni elaborar instrumentos que tengan algún tipo de eficacia jurídica. Pero la práctica internacional desmentiría, en parte, esta afirmación. Cabe recordar que un fenómeno similar a la Cumbre de las Américas, como es el caso de las Cumbres Iberoamericanas, con todos los matices que se quiera, ha procedido, sin embargo, de otra forma ${ }^{5}$.

de Derecho Internacional de Vitoria-Gasteiz-Vitoria-Gasteizko nazioarteko zuzenbide ikastaroak, 1995, núm. 1, pp. 195-266.

2 Un trabajo sobre estas relaciones: Domínguez GuADARrama, R., «Cuba y Estados Unidos: el largo proceso del reconocimiento», Latinoamérica, vol. 60, 2015, núm. 1, pp. 53-92. La posibilidad de un acuerdo entre Cuba y los Estados Unidos ya se vislumbró en la anterior Cumbre, en Cartagena de Indias. Véase Malamud Rikles, C. D. y García-Calvo Rosell, C., "La V Cumbre de las Américas: las relaciones entre Cuba y Estados Unidos se juegan en la isla», Análisis del Real Instituto Elcano (ARI), vol. 74, 2009, pp. 1-8.

3 Toríbio Dantas, A., «El fracaso del ALCA y el MERCOSUR», Estudios, vol. 18, otoño de 2006, pp. 73-81, en particular, pp. 76 y ss. También GambOA UMAÑA, L. E., «El área de libre comercio de las Américas -ALCA—: tareas y retos ante un proyecto de integración», Revista Espiga, vol. 3, 2002, núm. 6, pp. 75-102.

4 Valdez Carrillo, J., Navarro González, A., Frassoni, M. y Meyer, W., "La diplomacia de las cumbres», en Alcántara Sáez, M. y Salvadora Ortiz, M. (coords.), Relaciones entre América Latina y Europa: balance y perspectivas, Salamanca, Universidad de Salamanca, 2008, pp. 157-194.

5 La labor que desarrollan estas Cumbres ha producido la adopción de acuerdos en materia de seguridad social y se han aprobado algunos instrumentos que, teniendo también una naturaleza política, recogen principios, derechos y obligaciones de carácter jurídico, como es la «Carta Cultural Iberoamericana» y el "Consenso sobre Desarrollo y Migraciones», adoptados en Montevideo, en 2006. Por todos, DíAZ BARRADo, C. M., «La Carta Cultural Iberoamericana: una pieza básica para la configuración de un espacio cultural iberoamericano», en Badia Martí, A. M., Pigrau i Solé, A. y Olesti Rayo, A. (coords.), 
Todo permite decir, a lo sumo, que la Cumbre de las Américas realiza el cometido de servir de impulso para el diálogo, la concertación política y la cooperación internacional entre los Estados de la región y que, en principio, no le corresponde ser un recipiente que fragua la adopción de acuerdos internacionales o formular declaraciones que tengan valor jurídico. Dos motivos, al menos, explican que esto sea así: por un lado, la Cumbre no es la expresión de una Organización internacional, carece de voluntad propia distinta de la de los Estados que participan y, además, no dispone de órganos permanentes que aseguren su personalidad jurídica y que potencien labores normativas; por otro lado, las relaciones entre la Cumbre y la Organización de Estados Americanos (OEA), que actúa como secretaría técnica de las Cumbres, resaltan que los ámbitos de actuación de una y otra son prácticamente similares, excluyendo quizá el inicial énfasis que la Cumbre puso en los aspectos económicos. Por ello, de la labor normativa se encarga más bien la OEA y no los Estados reunidos en el seno de la Cumbre.

De ahí la conclusión resulta sencilla: la Cumbre está destinada, en el mejor de los casos, a constituir un punto de referencia en torno a principios, guías, orientaciones y pautas que expresan los Estados en sus relaciones mutuas que quizá pudieran encontrar plasmaciones normativas en escenarios y realidades muy distintos. Ahora bien, puesto que el contexto de cooperación e integración en América es sumamente abigarrado y complejo ${ }^{6}$, también se deja sentir en estas expresiones la influencia de las posiciones adoptadas en la Cumbre. Con todo, cabría decir que la Cumbre aún naciendo, como se ha dicho, "con el propósito de crear un espacio de discusión y toma de decisiones en lo referente a las problemáticas que competen a los países del Hemisferio Occidental ${ }^{7}$, ha propiciado decisiones que tienen un marcado carácter político y que no se plasman en acuerdos o instrumentos jurídicos de ningún tipo. No obstante, la tarea que hay que realizar en el examen de esta Cumbre no acaba aquí. El objetivo debe ser buscar, precisamente, cuáles son las contribuciones que realiza al ordenamiento jurídico internacional o, en su caso, identificar los aportes, aunque sean escasos, a la formulación de principios jurídicos o de normas que establezcan derechos e impongan obligaciones. Para ello, resulta imprescindible abordar, al menos, dos dimen-

\footnotetext{
Derecho internacional y comunitario ante los retos de nuestro tiempo: Homenaje a la prof. Victoria Abellán Honrubia, vol. 1, Madrid, Marcial Pons, 2009, pp. 131-146. Tampoco las Cumbres Unión EuropeaAmérica Latina (en la actualidad Cumbres CELAC-UE) han producido en sí la adopción de acuerdos e instrumentos normativos. Por todos, Freres, C. y Sanahuja Perales, J. A., «Hacia una nueva estrategia en las relaciones Unión Europea-América Latina», en Freres, C. y Sanahuja Perales, J. A. (coords.), América Latina y la Unión Europea: estrategias para una asociación necesaria, Madrid, Icaria, 2006, pp. 23-104.

6 En particular, Rojas Aravena, F., "Cambios en el mapa político de América Latina y Caribe», Anuario CEIPAZ, vol. 6, 2013-2014, pp. 163-182; y DíAZ BARRADO, C. M., "Panorama de la integración económica en el continente americano: especial consideración del espacio América Latina y Caribe», en Fernández Liesa, C. R. y Cano Linares, M. Á. (coords.), Los procesos de integración ante la crisis financiera internacional, Madrid, Marcial Pons, 2012, pp. 167-198.

7 Ministerio de Educación Nacional, Colombia, https://www.mineducacion.gov.co/1621/article-110928.html.
} 
siones distintas pero complementarias: primero, establecer los rasgos que definen la evolución y desarrollo de la Cumbre y, por ende, los factores que perfilan su alcance y contenido; y segundo, reconocer aquellos principios que cimientan la Cumbre y cómo se formulan en la medida en que contribuyan, más o menos, a reforzar su naturaleza jurídica y sirvan de componente idóneo de la práctica internacional.

\section{CONFIGURACIÓN DE LA CUMBRE DE LAS AMÉRICAS: FACTORES POLÍTICO-JURÍDICOS DETERMINANTES}

El origen y evolución que ha experimentado la Cumbre tienen un carácter eminentemente histórico y político. Estos aspectos quedan reflejados en las posiciones de los Estados de la región y, además, en el diseño general que realizan este tipo de reuniones. La evolución, y las etapas por las que ha transitado la Cumbre, revelan la existencia de estos dos elementos. La Cumbre no se ha desarrollado exclusivamente en el ámbito de la retórica, pero tampoco las decisiones adoptadas han incidido plenamente en el campo de los resultados prácticos. Los instrumentos habitualmente adoptados han sido: una Declaración de índole esencialmente política que tan solo se encarga de fijar los lineamientos básicos que deben seguir los Estados; y, al mismo tiempo, Planes de Acción que se formulan en términos tan genéricos que, salvo raras excepciones, no establecen ningún tipo de compromiso del que deriven derechos y obligaciones ${ }^{8}$. Ahora bien, las raíces históricas que fundamentan la Cumbre y el entorno político, muchas veces cambiante, que propicia su celebración, están en la base de este fenómeno.

Así se refleja, por ejemplo, en la que podemos denominar «Cumbre constitutiva», en Miami, en 1994. Por un lado, los Estados expresan la voluntad de establecer marcos permanentes de cooperación puesto que, por primera vez en la historia, se produce una reunión de estas características. La Declaración de Miami ${ }^{9}$ rezuma la importancia del momento histórico en que se celebra como resultado final de las experiencias históricas compartidas por los Estados de la región. En cualquier caso, la lectura sosegada de los textos de las distintas Cumbres asegura que el factor histórico es una de las razones que han propiciado el surgimiento de una instancia de esta índole ${ }^{10}$. Por otro lado, la situación política en América ha sido un factor decisivo en la con-

\footnotetext{
8 En algún caso se adoptó un documento, como en la Cumbre de Cartagena, en 2012, denominado «Mandatos». Ilustrativa, para conocer esta Cumbre, la lectura de SARRIón, A., "Washington se queda aislada en Cartagena: La Cumbre de las Américas ahonda la brecha entre el norte y el sur», El Siglo de Europa, 2012, núm. 969, pp. 46-48. No obstante, en algunas de las Cumbres celebradas se adoptan declaraciones especiales.

${ }_{9}$ Como se sabe, esta Declaración es el principal instrumento político-jurídico que emana de la I Cumbre de las Américas: http://www.summit-americas.org/i_summit_sp.html.

${ }_{10}$ BRICEÑo RUIZ, J., «Del panamericanismo al ALCA: la difícil senda de las propuestas de una comunidad de intereses en el continente americano (II)», Anuario Latinoamericano Ciencias Políticas y Relaciones Internacionales, vol. 4, 2017, pp. 139-162.
} 
formación de la Cumbre y, también, en su contenido. Esto se aprecia en la Primera Cumbre. La Declaración final sitúa los acentos en los componentes políticos que comparten prácticamente todos los Estados de la región. Se dice, con rotundidad, que: «Por primera vez en la historia, las Américas son una comunidad de sociedades democráticas. Si bien nuestros países enfrentan diferentes desafíos en materia de desarrollo, están unidos en la búsqueda de la prosperidad a través de la apertura de mercados, la integración hemisférica y el desarrollo sostenible. Estamos decididos a consolidar y fomentar vínculos más estrechos de cooperación y a convertir nuestras aspiraciones en realidades concretas» ${ }^{11}$. No obstante, las posiciones cambian a medida que se producen alteraciones políticas más profundas en los Estados de la región y se transforman radicalmente a partir de finales del decenio de los noventa del siglo $\mathrm{Xx}^{12}$.

La voluntad de conformar un marco de concertación política y cooperación internacional se ha logrado en poca medida y, en ningún caso, se han alcanzado los objetivos que cabría esperar, y querían los Estados, y que quedan expresados en la Declaración de Miami. En esta ocasión, se dice que: «Nuestra Declaración constituye un conjunto de compromisos integrales que se refuerzan mutuamente con miras a alcanzar resultados concretos» ${ }^{13}$. La clave está en que la Cumbre busca introducir la «noción de integración» y que el fracaso en la «integración económica» conlleva privar de mucho de sus contenidos a las decisiones que se han ido adoptando. Las fórmulas jurídicas empleadas se puede decir que no han sido las más idóneas ${ }^{14}$. Por lo menos, hubiera sido conveniente determinar un marco jurídico más preciso del quehacer de la Cumbre y su papel como principal impulsor de acuerdos y posiciones comunes de los Estados que participan.

\subsection{La Cumbre de las Américas como expresión del panamericanismo: la escasa incidencia en la dimensión jurídica}

El fenómeno del panamericanismo, aunque no se explicite, siempre está presente en muchos de los esfuerzos de cooperación e iniciativas de integración que tienen lugar en la región americana. La Cumbre responde a esta

\footnotetext{
11 http://www.summit-americas.org/i_summit_sp.html.

12 Véase Ullán de la Rosa, F. J., «La Alianza Bolivariana para las Américas-Tratado de Comercio de los Pueblos (ALBA-TCP): Análisis de un proyecto de integración regional latinoamericana con una fuerte dimensión altermundialista», Revista Venezolana de Ciencia Política, vol. 37, enero-junio de 2010, pp. 33-69.

13 http://www.summit-americas.org/i_summit_sp.html.

14 Tres trabajos, sin embargo, ofrecen algunas indicaciones en este sentido. Véanse en la obra de Rojas Aravena, F. (ed.), Globalización, América Latina y la Diplomacia de Cumbres, Santiago, FlacsoChile, 1998: Tluchín, J. S., "La Cumbre y la institucionalidad hemisférica», pp. 255-258; Van KLAVEREN, A., «Construyendo la institucionalidad hemisférica», pp. 259-264; y, además, STORK, J., «El Proceso de la Cumbre de las Américas en perspectiva: cambio global, normas regionales y capacidad estatal», pp. 265-288.
} 
realidad puesto que reúne los dos aspectos que mejor definen el panamericanismo. Como se ha dicho, este «buscaba encontrar sus raíces en dos factores: El primero, de naturaleza geográfica. El segundo de naturaleza histórica. El geográfico era obvio en sí mismo y respondía a la realidad de ese intenso continente, situado entre dos océanos [...]. El histórico, por su parte, aludía a la condición de civilizaciones trasplantadas desde el otro lado del océano, que compartían la América anglosajona y la América Ibérica, así como al episodio común de emancipación vivida por ambas» ${ }^{15}$. Hacía falta, por tanto, una reunión al más alto nivel que, más allá de la configuración de la OEA, estableciese una instancia encargada de exponer las indicaciones, pautas y orientaciones que debían seguir los Estados americanos en las labores de cooperación internacional y en las «propuestas de integración» que tienen lugar.

La idea de una "unión hemisférica» define la esencia de la Cumbre. Los énfasis se sitúan, sin embargo, en perspectiva práctica, en la «integración hemisférica de carácter económico». Por esto la Declaración de Miami reafirma, sin ambages, «el progreso que ya se ha obtenido a través de las acciones unilaterales de cada una de nuestras naciones y de los acuerdos comerciales subregionales de nuestro Hemisferio» y, así, "sobre la base de los acuerdos subregionales y bilaterales existentes ampliaremos y profundizaremos la integración económica hemisférica» ${ }^{16}$. Indirectamente, se trata de «dirigir» desde las orientaciones que propone la Cumbre una iniciativa que dé consistencia a la realidad panamericana, también en lo económico y no solo en lo político. Los escasos resultados de la Cumbre no expresan, sin embargo, el fin del panamericanismo, sino todo lo contrario. Las distintas etapas por las que ha transitado la Cumbre solo confirman la existencia de visiones encontradas de la realidad americana, pero, en ningún caso, ponen en entredicho la vigencia del fenómeno panamericano ${ }^{17}$. La Cumbre enlaza, con naturalidad, con la Conferencia Internacional Americana celebrada en Washington en 18891890, que no cabe olvidar que otorga un contenido preciso a la cooperación entre los Estados americanos en el ámbito comercial y que, además, abre la puerta a la adopción de decisiones que tendrán muchas plasmaciones jurídicas en los años posteriores ${ }^{18}$.

Ahora bien, importaría comprobar si las labores de la Cumbre contribuyen o no a conformar el denominado «Derecho internacional americano» ${ }^{19} \mathrm{O}$,

15 Morales Manzur, J. C., «La unidad continental: desde las concepciones geopolíticas hasta los nuevos modelos alternativos de integración», Congreso Latinoamericano de Ciencia Política, 12, 13 y 14 de junio de 2012, FLACSO, Ecuador, pp. 11-12.

16 http://www.summit-americas.org/i_summit_sp.html.

17 En sentido contrario, Alonso, A., «El siglo XXI y el ocaso del panamericanismo (un recorrido breve e incompleto a través de encuentros en la Cumbre)», Revista Casa de las Américas, julio-septiembre de 2015, núm. 280, pp. 50-57.

18 Siempre interesante, MANGER, W., «El Panamericanismo y las Conferencias panamericanas, Unión panamericana», Serie sobre Congresos y Conferencias, vol. 22, Washington, D. C. s/f, pp. 1-29.

19 Esta expresión ha sido abandonada pero no deja de existir una realidad normativa propia en América. Dos buenos trabajos: CAnçAdo Trindade, A. A., «The Contribution of Latin American Legal 
por lo menos, a la afirmación y consolidación de algunas normas en el ámbito del ordenamiento jurídico internacional. Es decir, merece la pena determinar el quehacer de esta Cumbre en el plano estrictamente jurídico, más allá de las posiciones y decisiones claramente políticas que adopta. Corresponde recordar que una seña de identidad del «panamericanismo» será la elaboración de un conjunto de principios y normas que integran un derecho dotado de características propias que, o bien son aplicables únicamente entre los Estados de la región, o bien trascienden y repercuten en la formación de normas en el plano universal ${ }^{20}$. Los compromisos de la Cumbre no permiten sostener que el ámbito jurídico sea una de las principales ocupaciones de los Estados de América. No se propone la celebración de acuerdos ni tampoco las decisiones adoptadas sirven de base para la elaboración de instrumentos jurídicos de alcance internacional. Más allá de alguna contribución al afirmar «principios estructurales» del orden internacional, que veremos más adelante, no existe una tendencia a que sirva de promotora de normas internacionales de las que deriven derechos y obligaciones. Se cumple lo que se dice, es decir, que la Cumbre reúne «a los jefes de Estado y de Gobierno de los Estados miembros del Hemisferio para debatir sobre aspectos políticos compartidos, afirmar valores comunes y comprometerse a acciones concertadas a nivel nacional y regional con el fin de hacer frente a desafíos presentes y futuros que enfrentan los países de las Américas» ${ }^{21}$.

Sin contradecir lo anterior, un examen detenido lo más que refleja es que los Estados se han expresado en una doble dirección a la hora de contribuir a la conformación jurídica de compromisos. En un caso, mediante la técnica de la simple referencia a instrumentos internacionales u Organizaciones internacionales que se encargan de elaborar o asegurar el cumplimiento de acuerdos o declaraciones que recogen derechos y obligaciones; en otro caso, quizá el más relevante, las primeras Cumbres proporcionaron el marco político preciso para que se abordase la adopción de un tratado en el campo del establecimiento de un espacio de Libre Comercio. Estas son, sin duda, las dos principales líneas que se advierten, siendo así que ninguna de ellas ha generado el nacimiento de «marcos normativos propios» y ni tan siquiera se ha alcanzado, por impulso y empuje de la Cumbre, la celebración de algún acuerdo internacional. En pocas palabras, en términos jurídicos se reiteran y refuerzan compromisos adquiridos o se orientan los trabajos en el seno de otras Organizaciones internacionales, sobre todo, en lo relativo a las labores que realiza la OEA. Por esto, se pudo decir, con ocasión de la Cumbre en

\footnotetext{
Doctrine to the Progressive Development of International Law», RCADI, vol. 376, 2015, pp. 9-92; y Villalta Vizcarra, A. E., "La contribución de América al Derecho Internacional», El Derecho Internacional en las Américas: 100 años del Comité Jurídico Interamericano, Rio de Janeiro, Secretaría General CJI, 2007, pp. 59-94. Disponible en http://www.oas.org/dil/esp/publicaciones_catalogo_digital_curso2006.htm.

20 Entre los mejores trabajos, ya clásico: YePES, J. M., El panamericanismo y el Derecho Internacional, Bogotá, Impr. Nacional, 1930.

${ }^{21}$ OEA, Cumbres de las Américas, Secretaría (página oficial), http://www.summit-americas.org/ defaults.htm.
} 
Puerto España (Trinidad Tobago), en 2009, que «una revisión de los escasos avances conseguidos en los temas planteados en la primera Cumbre en 1994 arroja que el "espíritu de Miami" (democracia y comercio) está muerto. Pero sobre sus cenizas nace una nueva era de relaciones entre Estados Unidos y América Latina» siendo así que «en el trasfondo se empieza a transformar el conjunto del sistema interamericano, con sus implicaciones para la democracia y el desarrollo en el hemisferio ${ }^{22}$.

i) Por lo que se refiere a lo primero, abundan expresiones que sustentan instrumentos internacionales consagrados de distinta naturaleza y contenido sin que se aprecie un importante aporte en cada uno de los campos que son objeto de atención. Más allá de las referencias genéricas al Derecho internacional, al Derecho internacional de los derechos humanos, al Derecho internacional humanitario y al Derecho de los refugiados ${ }^{23}$, destacan las menciones en ámbitos en los que se han adoptado instrumentos normativos. Sin agotar todas las posibilidades conviene reseñar: la aceptación de principios esenciales del orden internacional como se hace, como ejemplo significativo, en la Declaración de Quebec, en 2001, cuando los Estados expresan su "plena adhesión a los principios que obligan a los Estados a abstenerse de la amenaza o el uso de la fuerza, de acuerdo con el Derecho internacional» o a principios sectoriales asentados en el campo del Derecho internacional humanitario, al señalarse, en esta ocasión, la condena de ataques contra la población civil de los principios del Derecho internacional humanitario ${ }^{24}$.

También ha merecido una especial atención la aceptación de derechos sociales, en particular de contenido laboral, que se han reflejado en las Cumbres de Quebec, en 2001, y Mar del Plata, en 2005. En la primera se promueve «el cumplimiento de las normas fundamentales del trabajo reconocidas internacionalmente e incorporadas en la Declaración de la Organización Internacional del Trabajo (OIT) relativa a los Principios y Derechos Fundamentales en el Trabajo y su Seguimiento, adoptada en 1998 ${ }^{25}$; y, en la segunda, se le asigna «al derecho al trabajo tal como se encuentra estipulado en los instrumentos de derechos humanos un lugar central en la agenda hemisférica, reconociendo así el rol esencial de la creación de trabajo decente para alcanzar estos objetivos», siendo así que «asimismo aplicaremos medidas prioritarias y efectivas para prevenir y erradicar las peores formas del trabajo infantil de

22 Gratius, S. y Schulz, N. S., «La Cumbre de las Américas en clave europea», FRIDE, Policy Brief, abril de 2009, núm. 9, pp. 1-5, esp. p. 1.

23 Así se dice, por ejemplo, en la «Declaración de Mar del Plata», en 2005: «La promoción y protección universal de los derechos humanos incluidos los civiles, políticos, económicos, sociales y culturales, con base en los principios de universalidad, indivisibilidad e interdependencia, así como el respeto al Derecho internacional, incluidos el Derecho internacional humanitario, el Derecho internacional de los derechos humanos y el Derecho internacional de los refugiados, son fundamentales para el funcionamiento de las sociedades democráticas», Cuarta Cumbre de las Américas. Declaración de Mar del Plata, "Crear Trabajo para Enfrentar la Pobreza y Fortalecer la Gobernabilidad Democrática», http:// www.summit-americas.org/iv_summit_sp.html, p. 12, párr. 63.

${ }_{24} \mathrm{Cfr}$. http://www.summit-americas.org/iv_summit_sp.html.

${ }_{25}$ http://www.summit-americas.org/iii_summit_sp.html. 
acuerdo al Convenio 182 de la OIT (1999)» ${ }^{26}$. Por si fuera poco, se incide en la necesidad de cumplir algunos instrumentos internacionales específicos en esta materia y, por esto, la Declaración de Mar del Plata reseña «el valor de la Convención Internacional sobre la Protección de los Derechos Humanos de todos los Trabajadores Migrantes y de sus Familias» ${ }^{27}$.

Otro campo que recibe un tratamiento similar es el relativo a los «derechos de la propiedad intelectual», donde la Cumbre se limita a sustentar aquellas posiciones normativas que han expresado algunas Organizaciones internacionales. La Declaración de Mar del Plata indica que «la protección y la observancia de los derechos de propiedad intelectual deberán contribuir a la promoción de la innovación tecnológica y a la transferencia y difusión de la tecnología», por lo que se expresa el compromiso de proteger estos derechos en el marco del "Acuerdo sobre los Aspectos de los Derechos de Propiedad Intelectual relacionados con el Comercio de la $\mathrm{OMC}^{28}{ }^{28}$ No se trata, por tanto, de promover la adopción de normas específicas en esta materia y que estén orientadas a su aplicación en el espacio americano, sino que se aceptan, sin más, los principios y acuerdos que han tenido lugar en Organizaciones internacionales que se ocupan de este asunto. Ni en este caso ni en otros existe una voluntad de promover instrumentos normativos específicos ni tampoco que los Estados de la región estén dispuestos, desde la Cumbre, a iniciar una labor normativa en determinados campos o sectores del ordenamiento jurídico.

En definitiva, los documentos que adopta la Cumbre ponen de relieve que los Estados de la región están comprometidos con el cumplimiento y aplicación de instrumentos internacionales, siempre que estén aceptados o consagrados en el plano normativo, sin que se produzcan nuevas iniciativas para establecer un entramado jurídico, por lo menos, en aquellos sectores que merecen una especial atención por parte de la Cumbre. Lo que indica la Declaración de Puerto España cuando aborda el problema de las drogas y los delitos a los que puede dar lugar es una prueba fehaciente. Las expresiones que se utilizan no asumen más compromisos que los que se han recogido en instrumentos que han sido adoptados previamente ${ }^{29}$. Ni

\footnotetext{
${ }^{26}$ Cuarta Cumbre, op. cit., http://www.summit-americas.org/iv_summit_sp.html, p. 1, párr. 1 y p. 6, párr. 25.

27 Ibid. La incorporación de contenidos sociales deriva de los compromisos alcanzados en la Cumbre de Nuevo León, en 2004, que intentó «salvar» la iniciativa ALCA, puesto que se pensaba que carecía de aspectos de este tipo. En particular sobre esta Cumbre: Odello, M. E., «La Cumbre Extraordinaria de las Américas de Monterrey», Saberes, Revista de Estudios Jurídicos, Económicos y Sociales, vol. 3, 2005, pp. 1-22.

${ }_{28}$ Cuarta Cumbre, op. cit., http://www.summit-americas.org/iv_summit_sp.html, p. 9, párr. 48.

29 En esta ocasión, se dice que «incrementaremos nuestros esfuerzos para prevenir y combatir todos los aspectos del problema mundial de las drogas y los delitos conexos, mediante el fortalecimiento de la cooperación internacional y un enfoque integral y equilibrado, con base en el principio de responsabilidad común y compartida, de conformidad con los principios contenidos en las Cartas de las Naciones Unidas y de la OEA, el Derecho internacional y nuestros marcos legales aplicables», ibid. No cabe olvidar, sin embargo, que en la VI Cumbre, celebrada en Cartagena, se adoptó, sin mayor trascendencia, un «Comunicado de los jefes de Estado y de Gobierno sobre la realización de la Conferencia
} 
siquiera se apuntan algunos de los componentes singulares que podrían contribuir a enriquecer los instrumentos adoptados por el ordenamiento jurídico internacional, por el orden americano y por los ordenamientos jurídicos internos.

ii) Por lo que se refiere a lo segundo, en su nacimiento la Cumbre está marcada por la voluntad de otorgar al "panamericanismo» una dimensión económica. Esta es la razón última de la celebración de la Cumbre, por mucho que se hayan indicado múltiples motivos que aconsejaban que tuvieran lugar reuniones de este tipo. La evolución en los Estados de la región será lo que frene la iniciativa de constituir a la Cumbre en un motor que facilite y promueva la «integración económica». Por de pronto, la Declaración de Miami expresa con extraordinaria claridad que «decidimos iniciar de inmediato el establecimiento del "Área de Libre Comercio de las Américas" en la que se eliminaran progresivamente las barreras al comercio y la inversión. Asimismo, resolvemos concluir las negociaciones del "Área de Libre Comercio de las Américas” a mas tardar en el año 2005, y convenimos en alcanzar avances concretos hacia el logro de este objetivo para el final de este siglo» ${ }^{30}$. Aquí sí que estamos ante un verdadero compromiso político que debe tener necesariamente traducción jurídica y que revela que la Cumbre no está privada de mecanismos que le impidan promover, facilitar y proporcionar un marco jurídico en el que se realicen acuerdos en determinados ámbitos de la cooperación $^{31}$.

La práctica ulterior demuestra que la voluntad de establecer un espacio de integración económica y comercial, también en el ámbito de las inversiones, debería tener resultados prácticos que tan solo se pueden obtener si se abordan negociaciones que conduzcan, al final, a la celebración de un acuerdo internacional que recoja derechos y obligaciones para los Estados parte. Así, desde el principio, comenzaron las negociaciones para la creación de ALCA, que culminaron. No obstante, se detuvo el proceso definitivamente en la Cumbre de Mar de Plata, en 2005. Las expresiones que utiliza esta Cumbre no dejan lugar a dudas y suponen un alarde de «diplomacia de las palabras». En un mismo documento se acuerdan dos posiciones contradictorias. La Declaración de 2005 reconoce, por un lado, que «algunos miembros sostienen que tengamos en cuenta las dificultades que ha tenido

\footnotetext{
internacional de ministros de Relaciones Exteriores y jefes de organismos nacionales especializados contra el problema mundial de las drogas», OEA/Ser.E, CA-VI/CO.4/12, Cartagena de Indias (Colombia), 15 de abril de 2012. Quizá, más importancia tenga, en temas de seguridad el «Comunicado de las jefas y los jefes de Estado y de gobierno de las Américas para enfrentar y combatir la delincuencia organizada transnacional en el hemisferio», OEA/Ser.E , 14 y 15 de abril de 2012.

30 http://www.summit-americas.org/i_summit_sp.html.

31 Algunos títulos: Díaz Barrado, C. M. y Olmos Giupponi, M. B., «Características y dimensiones de la integración hemisférica en el continente americano: el Área de Libre Comercio de las Américas (ALCA)», en VARgas Gómez-Urrutia, M. y Salinas de Frías, A. (coords.), Soberanía del Estado y derecho internacional: homenaje al profesor Juan Antonio Carrillo Salcedo, vol. 1, Sevilla, Publicaciones Universidad de Sevilla, 2005, pp. 465-494; y Moreno, C., "Integración Latinoamericana: ALCA v. ALBA, Presente y Pasado», Revista de Historia, año 12, enero-junio de 2007, núm. 23, pp. 155-178.
} 
el proceso de negociaciones del Área de Libre Comercio de las Américas (ALCA), [...] mantenemos nuestro compromiso con el logro de un Acuerdo ALCA»; y, por otro lado, "otros miembros sostienen que todavía no están dadas las condiciones necesarias para lograr un acuerdo de libre comercio equilibrado y equitativo" ${ }^{32}$. En resumen, se pone fin a las negociaciones que debían conducir a la adopción de un tratado internacional que estableciese un espacio de Libre Comercio y se cierra la puerta a la misión de adoptar un tratado internacional que hubiera otorgado a la Cumbre una dimensión normativa.

El compromiso de la Cumbre de proceder a la integración económica tuvo, sin embargo, algunos resultados tangibles como la elaboración de borradores de tratado que recogían los compromisos que estarían dispuestos a asumir los Estados en la iniciativa de integración económica. En particular, en noviembre de 2003, culmina una fase de negociaciones que lleva a la elaboración detallada y minuciosa del Tercer Borrador de Tratado del Área de Libre Comercio de las Américas ${ }^{33}$. Este cuenta con venticuatro capítulos que detallan, en términos estrictamente normativos, los compromisos que implicaría la puesta en marcha de un espacio económico de esta índole y aborda disposiciones ambientales, laborales, medidas arancelarias y no arancelarias, agricultura, normas de origen, asuntos aduaneros, barreras al comercio, servicios, inversión y política de competencia, entre otras muchas materias. En verdad, un tratado amplio y detallado de Libre Comercio para una de las regiones más importantes del planeta, cuya adopción hubiera supuesto un cambio decisivo en el panorama de la integración. Interesa subrayar, sin embargo, que la elaboración de este Borrador, y los anteriores, prueba que la Cumbre no está incapacitada para servir de base en la elaboración de instrumentos jurídicos y que, por ende, no está condenada a constituir una mera instancia que tan solo proceda a formular orientaciones y pautas que, a lo sumo, tengan contenido político y, normalmente, un simple carácter retórico.

En resumen, la clave para determinar la eventual proyección normativa de la Cumbre está en que tenga lugar, al mismo tiempo, la confluencia de dos factores: primero, que las declaraciones que adopta dejen claro que asumen un compromiso político en una determinada materia y que se exprese con nitidez y concisión, como fue el caso de la voluntad de constituir un espacio de Libre Comercio; y, segundo, que se trate de un sector de la cooperación entre los Estados de América que no esté cubierto por otras Organizaciones internacionales de la región que ejerzan en exclusividad la competencia en ese sector. En realidad, la OEA no ha penetrado en la «integración económica» en la región y, por lo menos, no se ha suscitado en su seno la creación de un espacio de Libre Comercio en los términos en los que se lanzó ALCA.

\footnotetext{
32 Cuarta Cumbre, op. cit., http://www.summit-americas.org/iv_summit_sp.html, p. 4, párr. 19 y p. 5, párr. 19B.

33 http://www.ftaa-alca.org/ftaadraft03/index_s.asp.
} 


\subsection{La cambiante situación política en la Cumbre: la inevitable falta de acuerdos}

Una razón que ha propiciado que la Cumbre carezca de todo tipo de compromiso jurídico ha sido, con seguridad, «los vaivenes» a los que han estado sometidas cada una de las Cumbres y que derivan de los cambios políticos, a veces profundos, que se han producido en la región desde 1994 hasta nuestros días. La VIII Cumbre que ha tenido lugar en Lima, en 2018, se ha cerrado precisamente con el titular de que se ha puesto fin a la «era bolivariana» ${ }^{34}$. Esta expresión indica en parte la realidad y, sobre todo, el examen de los contenidos de esta Cumbre descubre, a la luz de las Cumbres anteriores, cómo se han producido avances y retrocesos en estos eventos y, además, cómo la situación política de la región y en los Estados que participan ha impedido siempre que se logren los principales objetivos a los que responden. Ahora bien, la ausencia de logros en lo jurídico y, en consecuencia, en la conformación normativa e institucional de la Cumbre encuentra sus principales motivos en lo siguiente:

En primer lugar, asistimos, prácticamente desde el principio, a la pérdida de protagonismo de la Cumbre en la realidad del continente. Se podrían establecer algunas etapas en el desarrollo de la Cumbre y, así, afirmar que «las cumbres de las Américas han transitado desde su origen por tres etapas sucesivas: consenso, conflicto e indiferencia» ${ }^{35}$, lo cual se ajusta bastante a la realidad. En verdad, pronto se disipó el inicial consenso en torno a que la Cumbre sirviera como estímulo principal para el establecimiento de un espacio de Libre Comercio y, por tanto, la puesta en marcha de un esquema de integración económica y comercial, lo que implicaría la adopción de acuerdos y dotar a la Cumbre de un cierto papel en el ámbito jurídico. En particular, el surgimiento de otro tipo de Cumbres, sobre todo en América, va a condicionar, sobremanera, su desarrollo y va a hacer que termine constituyéndose en un mero marco de cooperación que no precisa, en modo alguno, de compromisos y decisiones de carácter normativo.

Por un lado, el interés de Brasil por conformar un espacio propio y singular para la integración propició el nacimiento de Cumbres entre los Estados suramericanos, pero, incluso, supuso la creación de una Comunidad Suramericana de Naciones, primero, y de una Unión de Naciones Suramericanas (UNASUR), después, precisamente durante el periodo en el que se hacen patentes los conflictos en el seno de la Cumbre de las Américas. La voluntad de la política exterior brasileña de constituir un Área de Libre Comercio de Suramérica (ALCSA) se enfrentó directamente al primer propósi-

34 «La cumbre de las Américas sentencia el final de la era bolivariana en la región», El País, 15 de abril de 2018.

35 DabÈnE, O., "¿Tienen Futuro las cumbres de las Américas y el interregionalismo?», Amérique Latine, Politicaloutlook, 2012. Les Études du CERI, diciembre de 2012, núms. 189-190, pp. 14-18, esp. p. 14. 
to que quedó plasmado en la Cumbre de Miami. Una decisión de este tipo debilitó el sentido y alcance de la Cumbre de las Américas y dejó un escaso margen de maniobra para que, desde esta, se adoptasen decisiones políticas que tuvieran algún tipo de transcendencia jurídica. Por esto, cabe coincidir en que «el proyecto del Área de Libre Comercio de las Américas (ALCA), particularmente después de la Cumbre de las Américas realizada en Mar del Plata, tiende a desgajarse en diversos acuerdos de libre comercio bilaterales y subregionales» ${ }^{36}$, pero también en iniciativas de carácter regional como UNASUR $^{37}$. En breve, buena parte de los Estados americanos se suman a una iniciativa que relega las eventuales decisiones que se pudieran adoptar en el seno de la Cumbre de las Américas y, además, pretenden crear un espacio para la concertación política y la cooperación e, incluso, para la integración en determinados sectores, que entorpece el futuro desarrollo de algunos de los presupuestos de la Cumbre.

Por otro lado, el papel secundario que llega a jugar la Cumbre queda certificado con la aparición de una nueva instancia en el espacio latinoamericanocaribeño que, en realidad, agrupa a todos los Estados de la región, excepto a los Estados Unidos y Canadá. La constitución de la Comunidad de Estados Latinoamericanos y Caribeños (CELAC) ${ }^{38}$ significa, también, que la Cumbre de las Américas no cumpla algunas de las funciones para las que fue creada y que no llegue a conformarse como una instancia desde la que se propongan decisiones y compromisos que, en su caso, alcancen algún tipo de contenido jurídico en los distintos campos que pueden ser objeto de la cooperación. La pérdida de protagonismo de la Cumbre se acentúa con la creación de un ente de esta índole que, en el fondo, se va a ocupar de las mismas materias de las que se encargan «las Cumbres del sistema de Miami» (aunque quizá con menos énfasis en lo económico). Es decir, en ambos casos, se tratan todos los sectores en los que es posible la colaboración entre los Estados americanos sin que se identifiquen compromisos específicos y sin que, tampoco, se llegue acuerdos vinculantes. CELAC y Cumbre de las Américas van a compartir, entonces, la singularidad de que atienden, prácticamente los mismos Estados en los dos casos, el conjunto de temas que preocupan en la región a través de un mecanismo de Conferencias internacionales, con la única finalidad de

36 SERBin, A., "América del Sur en un mundo multipolar: ¿es la Unasur la alternativa?», Revista Nueva Sociedad, enero-febrero de 2009, núm. 219, pp. 145-156, esp. p. 146.

37 Conviene consultar: Busso, A. «Unasur en el escenario del multilateralismo latinoamericano: Luces y sombras», OASIS: Observatorio de Análisis de los Sistemas Internacionales, 2016, núm. 24, pp. 45-67; Carvajal Aguirre, F., «UNASUR: Avances y limitaciones en la integración de América del Sur», Anales. Revista de la Universidad de Cuenca, vol. 57, julio de 2015, pp. 75-92; Cienfuegos MATEO, M. y SANAHUJa Perales, J. A. (eds.), Una región en construcción. UNASUR y la integración en América del Sur, Barcelona, Fundación CIDOB, 2010; y Díaz BARrado, C. M., «La Comunidad Suramericana de Naciones: propuestas y realizaciones», Revista Española de Derecho Internacional, vol. 57, 2005, núm. 2, pp. 639-663.

38 Muy en particular, Rojas AravenA, F., «La comunidad de Estados Latinoamericanos y Caribeños: ¿Una opción viable para consolidar el multilateralismo latinoamericano?», Foreign affairs: Latinoamérica, vol. 10, 2010, núm. 3, pp. 24-31; y RoJAS ARAVENA, F, «La Celac y la integración latinoamericana y caribeña. Principales claves y desafíos», Nueva sociedad, 2012, núm. 240, pp. 16-27. 
ofrecer orientaciones y pautas de comportamientos. Ni en uno ni en otro caso se llega a la adopción de acuerdos obligatorios para los Estados.

En segundo lugar, la política de los Estados Unidos, principal impulsor de la Cumbre de las Américas, está en el origen de que, a la postre, se carezca de todo tipo de compromiso político que tenga algún tipo de trascendencia jurídica. El único ámbito en el que los Estados Unidos estaban dispuestos a vincularse por obligaciones jurídicas era el relativo al establecimiento de un espacio de Libre Comercio mediante un tratado y nunca se contempló llegar a asumir obligaciones en cualquiera otro de los sectores en los que era posible la cooperación. A medida que aumenta el «desinterés» de los Estados Unidos por la celebración de la Cumbre se aleja también la posibilidad de que esta se constituya en el motor para la asunción de acuerdos internacionales entre los Estados. En sus orígenes, sin embargo, los Estados Unidos realizan un planteamiento que debería llevar necesariamente a establecer una red de acuerdos internacionales, al menos en el ámbito económico y comercial. Las palabras del presidente norteamericano G. Bush, en 1990, apuntaban en esta dirección cuando formuló la Iniciativa para las Américas. Así, señaló que era necesario "crear incentivos para reforzar el creciente reconocimiento de América Latina de que las reformas de libre mercado son la llave para el crecimiento sostenido y la estabilidad política. Los tres pilares de nuestra nueva iniciativa son comercio, inversión, y deuda. Para expandir el comercio, yo propongo que empecemos un proceso de crear un zona hemisférica de libre comercio; para incrementar la inversión, que adoptemos medidas para crear un nuevo flujo de capital dentro de la región; y para fomentar la disminución de la carga de la deuda, un nuevo enfoque a la deuda de la región con importantes beneficios para nuestro medio ambiente» ${ }^{39}$. Expresiones como estas llevan a pensar, sin duda, en la celebración de tratados que hagan efectivos objetivos de este tipo ${ }^{40}$.

La ausencia de voluntad por los Estados Unidos de adoptar posiciones sólidas en la Cumbre hace también que esta instancia comience a perder influencia en la región y, sobre todo, que se constituya realmente como «una ocasión retórica». Los Estados participantes no están dispuestos a deducir consecuencias jurídicas de ningún tipo en los campos en los que sería posible la cooperación mutua. Todo deriva del «abandono» de la iniciativa ALCA y de las razones que están detrás de su fracaso, puesto que, como se ha dicho, «con el estancamiento de las negociaciones del ALCA, los países replantearon inmediatamente sus estrategias comerciales en la región», siendo así que «el vacío del ALCA está siendo llenado con una red de acuerdos bilaterales de última generación entre gran parte de los países que participaron en este proceso. Primero se negociaron acuerdos con los Estados Unidos de América y re-

39 Citado por Brunelle, D., «Los Estados Unidos, el ALCA, y los parámetros de gobierno global», Observatoire des Amériques, La Chronique des Amériques, octubre de 2004, núm. 33, http://www.ieim. uqam.ca/spip.php?page $=$ article-ameriques\&id_article $=3068 \& l a n g=f r$.

${ }^{40}$ Un trabajo siempre de interés del primer periodo e inicios en la conformación de la Cumbre: PAZ BARNICA, E., op. cit., nota 1. 
cientemente se observa un mayor interés en profundizar y afianzar los lazos comerciales a través de acuerdos entre los demás participantes del ALCA» ${ }^{41}$. No obstante, la política exterior norteamericana se ha ido desentendiendo de la Cumbre y, desde luego, ha dejado claro que no está dispuesta a impulsar acuerdos, una vez que ha quedado comprobado el fin del ALCA en la región.

Por último, aunque el escaso liderazgo que quieren asumir los Estados Unidos en la Cumbre explica que esta carezca de todo contenido normativo e institucional, esto deriva también de la posición de buena parte de los Estados latinoamericanos y caribeños. Estos interpretan que deben prescindir de esta instancia como un marco idóneo para la adopción de acuerdos. Se aprecian, al menos, dos comportamientos en este sentido. En una primera etapa, que comienza cuando se pone fin al "periodo de consenso», el único objetivo de muchos Estados de la región parece ser impedir que se instaure el ALCA y, por tanto, expresan su voluntad de no celebrar un acuerdo de esta índole del que deriven obligaciones. Curiosamente, esta actitud se mantiene a pesar de que continúa la negociación del Acuerdo ALCA y se formulan propuestas para mejorar su contenido, sobre todo, en los aspectos relativos a la «dimensión social» de la integración y la toma en consideración de los distintos niveles de desarrollo de los Estados que participan en la iniciativa ${ }^{42}$. Pero, en una segunda etapa, la única preocupación de muchos de los Estados latinoamericanos y caribeños es «doblegar» algunos aspectos de la tradicional política de los Estados Unidos en relación con América Latina. De ahí que buena parte de algunas de las Cumbres que se realizan se destine tan solo a resolver la posición que debe ocupar Cuba en la "diplomacia del continente» y asegurar su inserción completa en la región. Tan es así que, a pesar de los principios que proclama la Cumbre de las Américas, estos Estados latinoamericanos y caribeños logran que Cuba llegue a participar como un actor más de la región ${ }^{43}$. En definitiva, la posición de buena parte de los Estados de América Latina y el Caribe no está por la labor de que la Cumbre sirva como una plataforma para la asunción de obligaciones jurídicas en determinadas materias y tan solo se concibe como un espacio para "la confrontación política» entre dos visiones muy distintas de la realidad de América.

\section{CONTRIBUCIÓN DE LA CUMBRE EN LA FORMACIÓN DE PRINCIPIOS DEL ORDEN INTERNACIONAL}

Los instrumentos que se han adoptado en la Cumbre y que se han plasmado, básicamente, en Declaraciones y Planes de Acción, revelan posiciones

\footnotetext{
41 Chávez Núñez del Prado, B., «El nuevo bilateralismo y el ALCA», Agenda Internacional, año XIII, 2007, núm. 24, pp. 115-138, esp. pp. 117 y 137.

42 Véase CAStro Escudero, A., "ALCA: ¿proyecto de integración viable?», Comercio exterior, vol. 48, 1998, pp. 820-825.

43 Todo el proceso previo en Domínguez GuadarRama, R., «Cuba y Estados Unidos: el largo proceso del reconocimiento", Latinoamérica, vol. 60, 2015, núm. 1, pp. 53-92.
} 
políticas de las que cabría extraer algunas consecuencias jurídicas, al menos, en el sector concerniente a principios que están recogidos o formándose en el ordenamiento internacional o que están cristalizando en el ámbito de la realidad americana. Este sería un campo en el que se podrían advertir algunas contribuciones de la Cumbre en el ámbito del Derecho internacional. No interesa tanto, sin embargo, detallar las posiciones de los Estados en la Cumbre, a la hora de afianzar o proclamar su adhesión a principios plenamente consagrados y asentados en el orden internacional o, en su caso, en un hipotético «Derecho regional americano», sino más bien comprobar si verdaderamente la Cumbre cumple también el papel de permitir la cristalización de principios jurídicos que están madurando y que, con el tiempo, podrían llegar a ser parte del ordenamiento jurídico internacional.

En esta perspectiva, no sería necesario analizar la postura de la Cumbre, por ejemplo, en materia de reconocimiento y protección de los derechos humanos. El principio que sustenta la defensa de estos derechos está completamente integrado en el orden internacional, con pleno valor jurídico. Lo único que podríamos decir es que la Cumbre, en efecto, ha destinado algunos esfuerzos por señalar la importancia de este principio y, asimismo, la adhesión de los Estados de América a las obligaciones que dimanan de un principio así ${ }^{44}$. Poco nuevo se añade en este sentido que no esté recogido en otros instrumentos internacionales. La clave no está en reconocer que las posiciones, en materia de derechos humanos, afianzan un principio estructural del orden internacional, con valor y consecuencias jurídicas, puesto que se trataría de una aportación limitada sino, sobre todo, comprobar si la Cumbre establece un sistema singular de reconocimiento y protección de los derechos humanos. Algo que, en realidad, no sucede. En pocas palabras, la Cumbre no ha instaurado «un sistema particular» de protección de los derechos humanos ni ha asumido compromisos jurídicos específicos en esta materia. Tan solo se ofrecen indicaciones sobre cuáles deben ser los comportamientos de los Estados en materia de derechos humanos ${ }^{45}$.

Queda claro, entonces, que no interesa analizar lo que se refiere a principios que están consagrados y plenamente vigentes en el orden internacional. Resulta más interesante examinar aquello que contribuye a afirmar principios que todavía no están aceptados unánimemente por la comunidad internacional y a los que las referencias de la Cumbre, y el modo en que se realizan, pueden contribuir a su consolidación. En esta línea, no resulta fácil identificar esos principios de naturaleza eminentemente política pero

44 El valor de los derechos humanos en la Cumbre queda claro y se repite hasta la saciedad. La Declaración de Miami parte de la vinculación entre Democracia y derechos humanos y, en concreto, en el Plan de Acción se recoge un apartado singular respecto a la "promoción y protección de los derechos humanos», http://www.summit-americas.org/iii_summit_sp.html, punto I, apdo. 2.

45 Lo mismo cabe predicar del «principio» relativo al «desarrollo sostenible» mencionado, también, con reiteración. Para conocer este "principio» un trabajo de interés, en perspectiva jurídica, de hace tiempo: Bermejo García, R. y Douggan Beaca, J. D., "El derecho al desarrollo: un derecho complejo con contenido variable», Anuario Español de Derecho Internacional, vol. 8, 1985, pp. 211-249. 
que reciben un trato que está destinado a que, con el tiempo, formen parte integrante de los principios esenciales del orden internacional o, en su caso, como principios sectoriales en algunos de los campos que conforman el Derecho internacional contemporáneo. Seguramente, la labor de la Cumbre destaca, particularmente, en relación con dos "principios» que expresan "tendencias» muy claras en la actual sociedad internacional, siendo así que esta contribuye sobremanera a su cristalización, por lo menos en el ámbito americano y, más allá, quizá con un alcance también universal. En particular, el «principio democrático» que recibe un tratamiento similar en otras regiones del planeta como es en el caso europeo en especial ${ }^{46}$ pero que tiene sus especificidades en América. También, el "principio relativo al Libre Comercio» que hace tiempo que comenzó a ser considerado en perspectiva jurídica y no con parámetros exclusivamente económicos. Casi todas las Cumbres, sobre todo las primeras, incorporan referencias a estas nociones y su importancia se puede apreciar: primero, en que en la Cumbre están representados todos los Estados del continente americano con lo que la afirmación de «un nuevo principio» alcanzaría un significado al menos regional; y, segundo, en que la formulación que se hace de estos "principios» tiene probabilidad suficiente para que se determinen consecuencias jurídicas en el proceso de su conformación en el orden internacional ${ }^{47}$.

\subsection{El «principio democrático»: aportaciones específicas en el ámbito jurídico}

En la Cumbre se repite, como una especie de letanía, que la democracia no solo es el régimen político-jurídico que deben revestir los Estados de la región, sino que, además, supone un componente imprescindible para la cooperación entre los Estados. La propia constitución de la Cumbre responde a este objetivo. La Declaración de Miami afirma, con rotundidad y desde el principio, que «los jefes de Estado y de Gobierno elegidos de las Américas estamos comprometidos a fomentar la prosperidad, los valores y las instituciones democráticas y la seguridad de nuestro Hemisferio. Por primera vez en

\footnotetext{
46 Algunos títulos para el ámbito americano: Zela MartínEz, H., «The Organization of American States and its Quest for Democracy in the Americas», Yale Journal of International Affairs, vol. 23, 2013, pp. 23-36; CoOPER, A. F., "The Quebec City "democracy summit"», The Washington Quarterly, vol. 24, 2010, núm. 2, pp. 159-171; Dannenmaier, E., «Trade, Democracy, and the FTAA: Public Access to the Process of Constructing a Free Trade Area of the Americas», Fordham International Law Journal, vol. 27, 2003, núm. 4, pp. 1066-1117; AzPuru, D. y Shaw, C. M., «The United States and the Promotion of Democracy in Latin America: Then, Now and Tomorrow», Orbis, primavera de 2010, pp. 252-267; y Rodríguez Olivari, D., The Role of the Organization of American States in Promoting Democracy, IDEA, International Institute for Democracy and Electoral Assistance, 2014.

${ }^{47}$ La creación de la Cumbre responde a tres motivos que lo permiten, pues, como se señaló, "cette rencontre a été un succès notable pour trois raisons. Tout d'abord, le sommet a réussi à réunir 34 chefs d'État américains, soit les représentants de tous les pays de l'hémisphère sauf Cuba. Cette rencontre a ensuite permis de bâtir un agenda régional sur une variété de thèmes [...]. Finalement, les participants au Sommet de Miami ont mis en place une série de rencontres intergouvernementales qui ont assuré une progression dans la coopération interaméricaine», Migneault, D., op. cit., nota 1, p. 2.
} 
la historia, las Américas son una comunidad de sociedades democráticas» ${ }^{48}$. Ahora bien, la democracia no ha alcanzado la categoría de principio en el orden internacional y, a lo más, se advierte una "tendencia» a que llegue a ser, con el tiempo, uno de los presupuestos básicos, con implicaciones normativas, en este ordenamiento jurídico ${ }^{49}$. Se podría calificar, en realidad, como un "principio en formación» que recibe un sustancial apoyo por parte de muchos Estados de la comunidad internacional y que, en concreto, tiene trascendencia en algunas regiones del planeta, entre las que destaca el continente americano. Desde el inicio la Cumbre ha contribuido, en términos jurídicos, a la conformación de este principio, eso sí, en un marco más general de lo que acontece en las distintas instancias de cooperación y esquemas de integración que tienen lugar en la región ${ }^{50}$.

Así, podemos establecer dos conclusiones que son complementarias: primera, la Cumbre realiza una aportación específica y singular al «principio democrático»; y, segunda, esta contribución debe ser entendida también en relación con las posiciones que respecto al "principio» han adoptado otras instituciones e instancias americanas que se han ocupado de esta cuestión, en concreto, la significativa labor que ha desarrollado la OEA ${ }^{51}$ aunque, asimismo, se registran destacados logros en los distintos esquemas de integración americanos. La confluencia de ambos aspectos permite decir que la Cumbre estimula el reconocimiento universal del "principio democrático»y, sobre todo, consolida la validez, con efectos jurídicos, de la democracia en el orden regional americano ${ }^{52}$. En este sentido, se recuerda que, en la Cumbre de Quebec, en 2001, «fue iniciada la preparación de la Carta Democrática Interamericana, la cual reforzó los instrumentos de la OEA para defender activamente la democracia representativa hacia lo interno de la región» ${ }^{53}$. Esta estrecha vinculación entre el quehacer de la Cumbre y las tareas que desarrollan otras instancias americanas permite entender, con toda intensidad, la contribución

48 http://www.summit-americas.org/i_summit_sp.html. Para este apartado, véase también mi artículo en la Revista Electrónica de Estudios Internacionales, diciembre de 2018, núm. 36, titulado: «El "principio democrático" al hilo del Acuerdo sobre Diálogo Político y Cooperación entre la Unión Europea y Cuba».

49 Imprescindible la lectura para abordar esta cuestión de CHARLESWORTH, H., «Democracy and International Law», RCADI, vol. 371, 2014, pp. 43-152.

50 Muchas son las aportaciones a la noción de democracia en los esquemas regionales y subregionales de integración. Por todos, en los ámbitos de Mercosur y Comunidad Andina: Hummer, W., «El "Diálogo Político" y el Compromiso Democrático en las zonas de integración económica en América Latina», en Drnas de Clément, Z. (coord.), Libro Homenaje al Profesor Ernesto J. Rey Caro, Córdoba, República Argentina, Drnas-Lerner, 2002, pp. 1241-1280.

51 Conviene consultar al respecto, las precisiones que hace RoldAN BARBERo, J., Democracia y Derecho internacional, Madrid, Civitas, 1994.

52 Se ha dicho, que «la importancia de la Primera Cumbre [...], provino de plantear como factor político no negociable el apoyo al sistema democrático en el continente y facilitar el fortalecimiento de las bases que legitimaban el sistema político», Pérez TORO, J. A., «Democracia y Cumbre de las Américas», RAI, Revista Análisis Internacional, vol. 5, año 2012, pp. 65-103, esp. p. 74.

53 MaIhold, G., "Las Cumbres hemisféricas y su impacto regional-un balance», en Jarque, C. M., Salvadora Ortiz, M. y Quenan, C. (eds.), América Latina y la Diplomacia de Cumbres, Secretaría General Iberoamericana, octubre de 2009, p. 65. 
que la Cumbre realiza a la consagración, al menos en el plano regional, del "principio democrático» y las consecuencias jurídicas que se derivan de ello. Conviene, sin embargo, distinguir ambos planos, por lo menos a los efectos de una cabal comprensión de la verdadera aportación de la Cumbre en la formulación y aceptación de este principio.

i) La Cumbre ha desarrollado una ingente labor destinada a afirmar el "principio democrático» y darle un contenido más allá de lo político para que tenga, en suma, trascendencia en el ámbito jurídico. Las Cumbres celebradas hasta ahora confirman esta aseveración. Sin embargo, se observan algunas consecuencias prácticas más allá de las afirmaciones, a veces retóricas, en torno al criterio de la democracia. En particular, se acoge con naturalidad un concepto de democracia específico: «la democracia representativa» y no se tienen en cuenta, en concreto, otros modelos de democracia. La Declaración de Miami lo deja claro al decir que «la Carta de la Organización de los Estados Americanos establece que la democracia representativa es indispensable para la estabilidad, la paz y el desarrollo de la región. [...] La democracia se basa, entre otros principios fundamentales, en elecciones libres y transparentes, e incluye el derecho de todos los ciudadanos a participar en el gobierno» ${ }^{54}$. Esta posición se repite hasta la saciedad. Ahora bien, con el tiempo se advierte una probable contradicción, a partir de 2015, entre la afirmación del «principio democrático» y la aceptación de que algunos Estados, como Cuba, participen en el «sistema de Cumbres», lo que seguramente se explica porque se quiere establecer un marco de cooperación con la isla que le lleve paulatinamente al establecimiento de procedimientos de democracia representativa. La no invitación a Venezuela para que participase en la VIII Cumbre de las Américas, en Lima, en 2018, sin embargo, camina en una dirección contraria. En cualquier caso, comportamientos de este tipo no "contradicen», en esencia, la nítida tendencia de los Estados de la región que deben contar con un régimen democrático.

Asimismo, la Cumbre intenta extraer todas las consecuencias posibles de la afirmación del «principio democrático» y plantea, por tanto, los distintos sectores en los que podría tener efectos político-jurídicos. Así, por ejemplo, se comprueba cómo en la Declaración de Lima, en 2018, se destacan, dentro del concepto de "Gobernabilidad democrática frente a la corrupción», muchos de los sectores en los que incide el "principio», como el fortalecimiento de la gobernabilidad democrática, la transparencia, el acceso a la información, la protección de denunciantes y derechos humanos, incluyendo la libertad de expresión, o el financiamiento de organizaciones políticas y campañas electorales, entre otros. Esto, a pesar de que esta Cumbre no incide en el "principio» como tal. Los Planes de Acción de otras Cumbres conducen a la misma conclusión. En cualquier caso, la principal aportación de la Cumbre ha sido que se estableció, desde los inicios, un «mecanismo específico de reacción», aunque no detallado, frente a supuestos en los que

\footnotetext{
${ }^{54}$ http://www.summit-americas.org/i_summit_sp.html.
} 
se produce la ruptura del orden constitucional en alguno de los Estados de América ${ }^{55}$.

ii) La Cumbre recoge las experiencias en materia de democracia de otras instancias regionales y subregionales y las aglutina en una instancia más amplia para estimular su aceptación como "principio» rector de las relaciones entre los Estados, con consecuencias políticas y jurídicas. En concreto, se establece una estrecha vinculación entre la labor que realiza la Cumbre y los trabajos que ha realizado la OEA en el campo de la democracia. En puridad, los logros normativos de la OEA en relación con el «principio democrático» no son propios de la Cumbre, pero esta instancia sí ha procurado impulsar y perfilar algunos avances normativos que resultan notables en la Organización hemisférica. En esta línea, la adopción de la Carta Democrática Interamericana, en 2001, es un resultado de la tarea normativa que realiza la OEA pero encuentra un respaldo decisivo en las posiciones que asume la Cumbre. El propio Preámbulo de la Carta comienza destacando la «cláusula democrática» que se adoptó en la Cumbre de Québec. Además, todas las interpretaciones coinciden en señalar que esta Cumbre supone el origen de la adopción de la Carta, aunque su aprobación formal le sea atribuible a la OEA ${ }^{56}$.

Así, por ejemplo, lo indicó el Representante Permanente de Chile, en el momento oportuno: «El proyecto de Carta Democrática que acabamos de adoptar formalmente responde a la voluntad de nuestros jefes de Estado y de Gobierno. La cláusula democrática consagrada por ellos en la Declaración de Quebec será, a partir de su aprobación por nuestros cancilleres en Lima, el mecanismo preventivo y reparador para proteger la institucionalidad democrática contra cualquier intento de abolirla» ${ }^{57}$. Queda claro que el mandato político de Quebec se tradujo finalmente en un instrumento con eficacia jurídica y que, en este sentido, la Cumbre ha cumplido un papel esencial en su elaboración y contenido. No corresponde entrar ahora en el análisis de la Carta, pero sí resaltar que es también un resultado específico de la Cumbre que encontró traducción normativa a través de los procedimientos y mecanismos de la OEA que, desde hace tiempo, venía afirmando el «principio democrático» ${ }^{58}$. Este hecho resulta innegable y, por tanto, se debe sumar en el haber de la Cumbre. Con ello, se constata una contribución de la Cumbre a

55 Así, en Quebec, en 2001, se dice que «cualquier alteración o ruptura inconstitucional del orden democrático en un Estado del Hemisferio constituye un obstáculo insuperable para la participación del Gobierno de dicho Estado en el proceso de Cumbres de las Américas. Tomando debidamente en cuenta los mecanismos hemisféricos, regionales y subregionales existentes, acordamos llevar a cabo consultas en el caso de una ruptura del sistema democrático de un país que participa en el proceso de Cumbres», http://www.summit-americas.org/iii_summit_sp.html. Esto queda plasmado, con posterioridad en la Carta Democrática Interamericana.

56 Véanse las referencias en la obra: OEA, Carta Democrática Interamericana, Documentos e interpretaciones, Washington, DC, 2003.

57 Acta de la sesión ordinaria del Consejo Permanente de la Organización, celebrada el 6 de septiembre de 2001, Washington, DC, en OEA, Carta Democrática Interamericana, Documentos e interpretaciones, op. cit., nota 55, p. 61.

58 Gratius, S., «Diez años de la Carta Democrática Interamericana», FRIDE, Policy Brief, vol. 61, septiembre de 2011, pp. 1-5. 
la consolidación del «principio democrático» en el ámbito regional y, en consecuencia, se destaca la influencia que pudiera tener la Carta Democrática Interamericana en el plano universal ${ }^{59}$.

\subsection{El Libre Comercio como principio de las relaciones entre los Estados americanos: incertidumbres sobre su naturaleza y grado de aceptación}

El comienzo de la Cumbre estuvo marcado por la acogida de un principio, en el ámbito económico, que podría tener efectos en el plano jurídico. La búsqueda del Libre Comercio no solo como un objetivo básico para la integración hemisférica sino, también, como fundamento del comportamiento de todos los Estados de América. La Declaración de Miami es precisa en esta materia al decir que se pretende promover «la prosperidad a través de la integración económica y el libre comercio» puesto que «una clave para la prosperidad es el comercio sin barreras, sin subsidios, sin prácticas desleales y con un creciente flujo de inversiones productivas. La eliminación de los obstáculos para el acceso al mercado de los bienes y servicios entre nuestros países promoverá nuestro crecimiento económico». Para terminar diciendo que «el libre comercio y una mayor integración económica son factores clave para elevar el nivel de vida, mejorar las condiciones de trabajo de los pueblos de las Américas y proteger mejor el medio ambiente» ${ }^{60}$. La apuesta por el Libre Comercio es tan firme que pronto llega a convertirse en un "principio rector» que debe inspirar el comportamiento y las decisiones de los Estados de la región.

Ahora bien, en la comunidad internacional, al igual que no existe un criterio de legitimidad en el orden político, por lo que todo Estado puede establecer el régimen ideológico y político que estime más pertinente, tampoco se dispone de un criterio de "legitimidad económica», por lo que todo modelo económico, en esencia, es compatible con el ordenamiento jurídico internacional. En otros términos, el Libre Comercio no ha cristalizado todavía como un «principio estructural del orden internacional» y no parece que constituya, tampoco, un principio sectorial plenamente aceptado en el Derecho internacional económico, como norma consuetudinaria ${ }^{61}$. Las expresiones que recoge la Resolución 2625 (XXV) de la Asamblea General de Naciones Uni-

59 En particular: Olmedo GonzÁlez, H., «Diez años de la Carta Democrática Interamericana: un régimen internacional para la defensa de la democracia», Revista Electrónica de Estudios Internacionales (REEI), 2011, núm. 22, pp. 1-27.

60 http://www.summit-americas.org/i_summit_sp.html.

61 Un trabajo sobre este principio y la costumbre internacional: Mitchell, A. D. y Voon, T., «Free Trade Agreements and Public International Law», Legal Studies Research Paper, University of Melbourne, 2007, núm. 321, pp. 1-27 (disponible en https://ssrn.com/abstract=1123263). También conviene la lectura, en el marco de la labor de la Organización Mundial del Comercio (OMC) de PAUWELYN, J., «The rol of Public international law in the WTO: how far can we go?», AJIL, vol. 95, 2001, pp. 535578; Neuwahl, N. A. y WeILER, J. H. H. (eds.), «The EU, the WTO and the NAFTA-Towards a Common Law of International Trade», European Foreign Affairs Review, vol. 6, 2011, núm. 1, pp. 144-145. En la 
das en esta materia siguen vigentes, por ahora, al señalar que: «Todo Estado tiene el derecho inalienable a elegir su sistema político, económico, social y cultural, sin injerencia en ninguna forma por parte de ningún otro Estado» 62 . En definitiva, la consagración jurídica del «principio de Libre Comercio» no se ha producido, pero ello no quita que no exista una tendencia, más acentuada en algunas regiones del planeta, a consagrarlo con significado no solo político sino también jurídico, del que derivarían derechos y obligaciones. Precisamente esto sucede en el continente americano. La importancia que adquiere la Cumbre en este ámbito deriva, al menos, de dos consideraciones complementarias:

Por un lado, la mayor parte de los Estados americanos están embarcados en esquemas de integración en los que el Libre Comercio es una pieza esencial. Ello se ha plasmado en acuerdos que implican derechos y obligaciones para los Estados. En la práctica, los cuatro esquemas de integración subregionales en América (CAN, SICA, MERCOSUR, CARICOM) reconocen el valor político-jurídico del Libre Comercio. Pero, incluso, parte de los esquemas regionales de integración caminan también en esta dirección. Recientemente, la constitución de la Alianza del Pacífico ha subrayado el valor que tiene el Libre Comercio como "principio capital» de las relaciones entre los Estados. El Acuerdo Marco, de 2012, busca «construir, de manera participativa y consensuada, un área de integración profunda para avanzar progresivamente hacia la libre circulación de bienes, servicios, capitales y personas» ${ }^{63}$ [art. 3, párr. 1, apdo. a)]. Esto implica necesariamente la creación de un espacio de Libre Comercio como condición previa del resto de los estadios de la integración económica.

Mucho antes, cuando se constituía la Cumbre de las Américas, el Tratado de Libre Comercio de América del Norte (TLCAN), en 1994, concedió al Libre Comercio un papel sustancial para los Estados parte. Así, estos Estados «de conformidad con lo dispuesto en el art. XXIV del Acuerdo General sobre Aranceles Aduaneros y Comercio, establecen una zona de libre comercio» ${ }^{64}$ (art. 101), que es descrita con precisión a lo largo del tratado y que especifica los derechos y obligaciones que implica. Todo esto, a pesar de los recientes avatares que ha sufrido este tratado y que, en todo caso, ha supuesto el «triunfo» del Libre Comercio. En resumen, la práctica de la integración en

\footnotetext{
doctrina española resalta el trabajo de MANERo SALVADOR, A., Los tratados de libre comercio de Estados Unidos y de la Unión Europea, Barcelona, Bosch, 2018.

${ }^{62}$ Declaración sobre los principios de Derecho internacional referente a las relaciones de amistad y a la cooperación entre los Estados de conformidad con la Carta de las Naciones Unidas, A/RES/2625, de 24 de octubre de 1970.

${ }^{63}$ https://alianzapacifico.net/documentos/. Por todos, Pampillo Baliño, J. P., «La Alianza del Pacífico y la integración jurídica latinoamericana. Antecedentes, balance y perspectivas», en TREMOLADA Álvarez, E. (ed.), La arquitectura del ordenamiento internacional y su desarrollo en materia económica, Bogotá, Universidad Externado de Colombia, pp. 365-406, y Malamund, C., «La Alianza del Pacífico: un revulsivo para la integración regional en América Latina», Real Instituto Elcano, ARI, 2012, núm. 46.

${ }^{64}$ Organización de Estados Americanos, Sistema de Información sobre Comercio Exterior (SICE), http://www.sice.oas.org/Trade/nafta_s/CAP01.asp\#Pa.1.
} 
América confirma completamente que el Libre Comercio está bien arraigado y que comienza a percibirse como el componente económico principal en las relaciones entre los Estados de la región ${ }^{65}$.

Por otro lado, el Libre Comercio adquiere autonomía en la Cumbre y, además, le añade un valor especial como eventual principio de las relaciones económicas entre los Estados. Proclamar el Libre Comercio en la Cumbre significa que es aceptado por prácticamente todos los Estados de América y que, con ello, toda una región del planeta pondría al Libre Comercio como presupuesto básico de las relaciones económicas internacionales. Ahora bien, cabe hacer algunas precisiones. En primer lugar, las posturas en relación con el Libre Comercio han ido variando con el tiempo. Hasta la Cumbre de 2005, en la que fracasa el establecimiento de ALCA, se observa una plena adhesión a este principio, que va disminuyendo con el tiempo. A partir de entonces, ni siquiera la expresión «Libre Comercio» aparece en las Declaraciones finales de Cumbres posteriores. Esto debilita, sin duda, su consideración como «principio rector» de las relaciones entre los Estados de la región o, por lo menos, como fundamento básico en el plano hemisférico. En segundo lugar, la no adopción del Acuerdo ALCA ha privado de que se exprese un sólido compromiso con el Libre Comercio. La imposibilidad de alcanzar el acuerdo, que traducía en términos jurídicos los derechos y obligaciones que se derivan del Libre Comercio, lleva a pensar que todavía no puede hablarse de un principio plenamente asentado en el orden regional y que, a lo sumo, con base en el comportamiento de los Estados en otras instancias, se trataría de un «principio en formación» que tiene bastantes dificultades para su conformación jurídica. Pero el «abandono» del principio del Libre Comercio en la Cumbre no debe hacer olvidar, como hemos dicho, que a partir de 2005 se incrementa el número de acuerdos bilaterales en esta materia en América y que, por tanto, de manera más fragmentada, se sigue incidiendo en la validez política y jurídica de un principio así ${ }^{66}$. En verdad, se instaura una tupida red de acuerdos bilaterales y regionales de Libre Comercio en América a pesar de que se abandone el objetivo del Libre Comercio en el marco multilateral hemisférico.

Con todo, la regla del Libre Comercio no se concibe como principio del orden internacional del que deriven comportamientos obligatorios para los Estados, pero sí conforma «una práctica habitual» entre los Estados de la región. Las posiciones de la Cumbre han contribuido a asentar una regla de

65 Incluso en esquemas de integración con otra orientación ideológica, como la Alianza Bolivariana para los Pueblos de Nuestra América (ALBA), no debe sorprender que se acoja también la noción de Libre Comercio, aunque se le dé una visión distinta a la tradicional. En la XI Cumbre del ALBA-TCP, en 2012, se firmó un acuerdo para el establecimiento de un Espacio Económico del ALBA-TCP (ECOALBA-TCP) y a partir de entonces, se celebró un Acuerdo de Complementación Económica. Véase SISTEMA ECONÓMICO LATINOAMERICANO Y DEL CARIBE (SELA), «El ALBA-TCP como mecanismo de cooperación de alcance regional», Caracas (Venezuela), Secretaría Permanente, julio de 2013, SP/Di, núm. 4-13.

${ }^{66}$ En particular, SELA, «Estado actual del proceso de integración en América Latina y el Caribe», XLI Reunión Ordinaria del Consejo Latinoamericano, Caracas (Venezuela), 25 al 27 de noviembre de 2015, SP/CL/XLI.O/Di, núm. 15-15. 
conducta en materia de Libre Comercio que incorpora, al menos, los aspectos esenciales que existen en todo acuerdo de estas características. Más aún, en América son pocas las posturas que rechazan esta práctica más allá de decisiones políticas puntuales y coyunturales que expresen algunos Estados en función de criterios de política interna. Lo que se constata, en definitiva, es que se ha producido «el rápido crecimiento de zonas regionales de libre comercio» ${ }^{67}$ y que esto ha sucedido, en particular, en América, al hilo también de la filosofía que inspira la implantación de la Cumbre.

\section{CONCLUSIONES}

No resulta fácil determinar el papel que cumple la Cumbre de las Américas en la configuración del ordenamiento jurídico internacional. No se han dispuesto procedimientos normativos ni un sólido marco institucional que permitan avanzar en la plasmación de acuerdos de naturaleza vinculante y, ni tan siquiera, la Cumbre ha constituido una instancia que adopte declaraciones de las que quepa extraer algún tipo de consecuencia jurídica. A lo más, contamos con declaraciones meramente políticas que se sitúan, en algunas ocasiones, en el campo de la retórica. Las pautas, orientaciones e indicaciones de las Declaraciones finales de la Cumbre y los Planes de Acción no han sido suficientes, en la mayoría de los casos, para atestiguar decisiones y compromisos que estén dotados de cierta eficacia jurídica. La conclusión, por tanto, resulta clara: ni la Cumbre surgió específicamente como una instancia para estimular la adopción de acuerdos ni tampoco representa una oportunidad para la adopción de normas de las que deriven derechos y obligaciones. Como se ha indicado, lo más, es que «las Cumbres de las Américas, en el contexto del multilateralismo, han transformado la naturaleza y la dinámica del diálogo político en el hemisferio occidental, y han acelerado el proceso de integración regional. Sus mandatos se han convertido en guías para la superación estratégica de los problemas de las Américas, y por ello es responsabilidad de todos [...] propender por su ejecución y participar en sus mecanismos de seguimiento" ${ }^{68}$.

Ahora bien, sin contradecir lo anterior, la Cumbre no está incapacitada para cumplir funciones más allá de lo meramente político. El examen de la práctica depara que puede realizar algunos aportes en perspectiva jurídica. Por una parte, estuvo a punto de estar en la base del primer acuerdo de Libre Comercio entre «todos» los Estados de América. Las negociaciones para ALCA son resultado precisamente de la Cumbre y tienen lugar por un nítido compromiso político. Por otra parte, algunos principios del orden internacio-

67 Herdegen, M., Derecho Económico Internacional, Bogotá DC, Editorial Universidad del Rosario, diciembre de 2012, p. 187.

68 Castañeda Aponte, N. y Moya Mancipe, D. (redactores), Cumbres de las Américas: Gobierno y ciudadanía, Bogotá (Colombia), Red Democracia Activa y Ministerio de Relaciones Exteriores, agosto de 2009 , p. 3. 
nal en proceso de cristalización pueden recibir un decisivo respaldo a través de las posiciones que asuman Conferencias internacionales. El largo proceso de cristalización de la democracia como principio estructural del orden internacional encontró aportes significativos en la Cumbre. Así, el compromiso político expresado en Quebec, en 2001, está en la base principal de la adopción de la Carta Democrática Interamericana por parte de la OEA que tiene, sin duda, un cierto valor y eficacia jurídica. Pero, además, la maduración de una regla internacional relativa al Libre Comercio encuentra fundamento en las decisiones políticas de algunas de las Cumbres que se han celebrado. La realidad americana de cooperación e integración es sumamente compleja pero una instancia como la Cumbre, a veces espacio para la concertación y otras veces escenario para la confrontación, desempeña un papel en los ámbitos del diálogo y también ha promovido compromisos, a pesar de que tengan un escaso contenido normativo.

Es normal que el devenir de la Cumbre de las Américas quede condicionado básicamente por la situación política que impere en América y, en concreto, en los Estados que la conforman, pero, infortunadamente, la realidad americana proporciona muchos casos en los que priman mucho más los aspectos políticos más puntuales sobre la verdadera vocación de integración. En esta línea, ejemplo fehaciente de esta situación es la decisión de no continuar con la adopción de un tratado de Libre Comercio para toda América. Esto refleja, una vez más, que resulta preciso que las expresiones de la cooperación en el hemisferio cuenten, al menos, con algunos componentes de naturaleza jurídica. Los cambios políticos que se producen en los Estados de América condicionan demasiado las posiciones que se adoptan en la Cumbre. El interés inicial por desarrollar el "principio democrático» y por el establecimiento del Libre Comercio ha decaído, en la actualidad, por razones de este tipo. En todo caso, el examen de los «compromisos» que se expresan en la Cumbre desde su creación permite sostener la existencia todavía de un «acervo común» que incorpora algunos «compromisos políticos» que, con el tiempo, pudieran encontrar traducción jurídica.

\section{RESUMEN}

\section{LA CUMBRE DE LAS AMÉRICAS: UN ESPACIO PARA LA COOPERACIÓN SIN APENAS PROYECCIÓN NORMATIVA}

La práctica de la Cumbre de las Américas enseña que es una instancia destinada a la cooperación entre los Estados de la región que ha tenido una escasa labor normativa. No obstante, esta Cumbre cumple las condiciones precisas para que en su seno se adopten acuerdos de naturaleza jurídica y, sobre todo, sirve de estimulo para la proclamación de algunos principios esenciales que, con el tiempo, pueden formar parte del ordenamiento jurídico internacional. En ningún caso, más allá de los resultados concretos, debemos prescindir de instancias de este tipo en la configuración del Derecho internacional puesto que la realidad prueba que, muchas veces, las posiciones políticas de los Estados reciben, con el tiempo, una traducción jurídica. Por lo menos, con independencia de que finalmente no se adoptó un acuerdo sobre el establecimiento de un Área de Libre Comercio en las Améri- 
cas, la Cumbre ha puesto los acentos en el "principio democrático» que ha llegado a tener valor jurídico en la región y en el "principio de Libre Comercio» que, con seguridad, está en proceso de cristalización en el ámbito consuetudinario.

Palabras clave: conferencias internacionales, cooperación internacional, principio democrático, Acuerdos de Libre Comercio.

\section{ABSTRACT \\ THE SUMMIT OF THE AMERICAS: AN AREA FOR COOPERATION WITH LITTLE LEGAL PROJECTION}

The Summit of the Americas' practice shows us that it is a cooperation body between States of the region which has developed the little normative work. However, this Summit fulfils the precise conditions to allow States to adopt legal agreements within it. Above all, the Summit of the Americas encourages the proclamation of some essential principles which could eventually be part of the international legal order. Beyond the specific results, under no circumstances we should dispense with bodies of this type in the domain of International Law. In fact, often and many times, practice shows that political positions of States receive a legal translation. As it is known, the Summit adopted no agreement on the establishment of a Free Trade Area in the Americas. However, at least, the Summit of the Americas has focused in the «democratic principle» which has gained legal force in the region as well as in the "Free Trade principle» that, surely, in the field of customary law is in the process of crystallization.

Keywords: international conferences, international cooperation, democratic principle, Free Trade Agreements. 